\title{
Refletindo sobre os limites da leitura literária hoje
}

\author{
Patrícia Kátia da Costa Pina \\ Universidade do Estado da Babia (Salvador, Brasil)
}

Dilcélia Almeida Almeida Sampaio

Universidade do Estado da Babia (Salvador, Brasil)

RESUMO: ESTE ARTIGO DISCUTE ALGUNS DOS DESAFIOS QUE CERCAM A LEITURA DE LITERATURA NA CONTEMPORANEIDADE, EM FACE DAS NOVAS, DIFERENTES E SEDUTORAS MÍDIAS QUE NOS CERCAM. PREOCUPAM-NOS O LUGAR QUE O TEXTO LITERÁRIO OCUPA NO COTIDIANO DE JOVENS E ADULTOS HOJE. PARA TANTO, DISCUTIR-SE-ÃO AS TEORIAS DE COMPAGNON, YUNES, COSTA, CADEMARTORI, COSSON, ENTRE OUTROS, NO SENTIDO DE SE DEFINIR O ATO DA LEITURA COMO AÇÃO LÚDICA, QUE PREVÊ INÚMERAS POSSIBILIDADES DE MEDIAÇÃO.

ABSTRACT: THIS ARTICLE DISCUSSES SOME CHALLENGES FACED BY THE ACT OF READING LITERATURE IN THE ADVENT OF SEDUCING AND VARIED NEW MEDIA. WHAT INTERESTS US IS THE PLACE OCCUPIED BY LITERARY TEXT IN TEENAGERS' AND ADULTS' DAILY LIFE. WE ARE GOING TO DISCUSS COMPAGNON'S, YUNES'S, COSTA'S, CADEMARTORI'S, COSSON'S AMONG OTHERS, TRYING TO DEFINE THE ACT OF READING AS PLAYFUL ACT, WITH A GREAT NUMBER OF POSSIBLE MEDIATION.

PALAVRAS-CHAVE: LEITURA, LITERATURA, LIVRO.

KEYWORDS: READING, LITERATURE, BOOK. 
É preciso que haja um leitor para que o texto possa existir. Um livro fechado é apenas um objeto, aberto e lido passa a existir como uma produção de sentidos do leitor.

Marta Morais da Costa, Sempreviva, a leitura, p. 39

ós, que lidamos com as teias das palavras, quando discorremos sobre a leitura e os leitores, principalmente no âmbito do literário, costumamos partir de imposições verbais que, para nossos olhos e ouvidos, são plenas de sentido, mas que são absolutamente vazias para os nossos Outros. Assim, na epígrafe, nos deparamos com a necessidade da interação da obra com o leitor para que ela exista. Problema fértil para debate.

Aquilo que para nós, pesquisadores e professores das Letras, é indiscutivelmente fundamental para o crescimento do ser humano - a arte da palavra - para os demais seres humanos é algo ocioso e deslocado no mundo globalizado e computadorizado de hoje. O livro, qualquer que seja sua natureza, é mesmo só mais um objeto. Marta Morais da Costa afirma, que o livro e a leitura devem sempre estar vivos no cotidiano de crianças, jovens e adultos, uma vez que, ao ler um livro, o Sujeito ativa funções de percepção, memória, atenção, organização mental, curiosidade, as quais, em interação, promovem prazer e compensam as energias envolvidas no ato da leitura. Para ela,

[...] ler é sempre interpretar. Palavras ou imagens provocam de imediato no leitor e no espectador a busca de significados para o que vê. O exercício dessa capacidade humana de projetar sentidos sobre os textos resulta numa aprendizagem contínua (COSTA, 2009, p. 31).

O gosto pela leitura surge, paradoxalmente, do exercício da leitura. Conjugando a intelectualidade e a afetividade, esta como consequência daquela, o ato de ler pode transformar o leitor em um Sujeito de poder. A leitura, especialmente a leitura literária, não é uma experiência mística, é um ato material, e, nas palavras de Rildo Cosson, é um ato solitário que se desdobra em um ato solidário, o qual se caracteriza como "[...] um concerto de muitas vozes [...]" (COSSON, 2009, p. 27).

Entendemos a leitura literária, aqui, como instrumento de formação de sujeitos críticos, capazes de refletir acerca do mundo em que vivem e que constroem em seu cotidiano, interpretando-o. Mas sabemos que, hoje, o texto 
literário, embora bastante acessível, inclusive pelas inúmeras bibliotecas virtuais que disponibilizam obras gratuitamente, está cada vez mais distante dos jovens e adultos. Para Eliana Yunes,

Ler é inscrever-se no mundo como signo, entrar na cadeia significante, elaborar continuamente interpretações que dão sentido ao mundo, registrá-las com palavras, gestos, traços. Ler é significar e, ao mesmo tempo, tornar-se significante. A leitura é uma escrita de si mesmo, na relação interativa que dá sentido ao mundo (YUNES, 2009, p. 53).

$\mathrm{O}$ ato da leitura coloca o sujeito leitor no mundo, num processo simultâneo e recíproco de reconstrução. Ler dá ao mundo gamas novas de significação. Ler é transformar e transformar-se. O leitor torna-se Outro em relação a si mesmo. Não há neutralidade no ato da leitura - ler é uma travessia das múltiplas textualidades inscritas no texto verbal, não-verbal, literário, documental, científico, etc. E atravessá-las significa pôr em diálogo os repertórios previstos no texto/obra e os repertórios pertinentes a cada leitor/interlocutor empírico - ou seja, ler pode ser entendido como um dos jogos de poder possíveis na sociedade.

É Lígia Cademartori quem afirma: "A leitura não provoca apenas alteração mental, mas também física" (CADEMARTORI, 2009, p. 23). A leitura muda o homem, por dentro e por fora, e o torna capaz de produzir sentidos para o mundo. E é preciso enfatizar que a compreensão leitora se aplica à linguagem literária e a outras linguagens. Retomamos a argumentação inicial: os pesquisadores acima citados, que representam muitas outras vozes acadêmicas ligadas às questões acerca do leitor, da leitura e da literatura, têm plena consciência da importância de ler, principalmente, da relevância de ler literatura. Mas o restante do mundo contemporâneo não tem consciência disso. Em 2009, a editora da UFMG publicou um livro resultante da Conferência de Abertura da Cátedra de Literatura do Collége de France, proferida por Antoine Compagnon, no dia 30 de novembro de 2006. O título vem a calhar para nossa discussão: Literatura para quê?

Na era da internet, do iPad, do iPod, do Orkut, do Facebook, etc., qual a função do texto literário? Caso consigamos determinar a função da Literatura hoje, como levá-la às crianças, aos jovens e aos adultos que se comunicam por torpe- 
dos, que fragmentam, em suas mensagens rápidas, poemas, contos, adaptandoos às suas necessidades pragmáticas imediatas (CURCINO, 2009, p. 19-21), esvaziando-os dos valores artísticos que lhes foram atribuídos por séculos? Para que a Literatura hoje? No final de sua conferência, Compagnon declara:

Literatura para quê? A literatura é substituível? Ela sofre concorrência em todos os seus usos e não detém o monopólio sobre nada, mas a humanidade lhe convém e seus poderes continuam imensos; ela pode, portanto, ser abraçada sem hesitações e seu lugar na Cidade está assegurado. O exercício jamais fechado da leitura continua o lugar por excelência do aprendizado de si e do outro, descoberta não de uma personalidade fixa, mas de uma identidade obstinadamente em devenir (COMPAGNON, 2009, p. 56-57).

Então, a leitura literária, apesar de deslocada no universo midiático de hoje, permanece pertinente por implicar aprendizagem, crescimento, exatamente diante da sociedade contemporânea, que se constrói a partir da visibilidade e da simultânea fugacidade das situações, dos fatos, dos limites, das identidades. No que compete à literatura, Yunes e Pondé afirmam:

A obra literária é um objeto social; para que exista, é preciso que alguém a escreva e um outro a leia. Para fechar esse circuito, passa-se por muitas instâncias: a do editor, a do distribuidor e a do livreiro, isto é, a obra tem de circular, para eventualmente ser lida. Nesse sentido, iguala-se a qualquer produto produzido e consumido nos moldes capitalistas, uma vez que precisa ser comercializada (YUNES, PONDÉ, 1989, p. 38).

Quem a escreve, o faz inserido em um dado lugar e em um certo tempo, ou seja, não está isento das questões que angustiam o mundo que gera e condiciona a mão que digita, o computador que a arquiva e o leitor que irá interagir com ela num primeiro momento e, também, em posteriores apropriações. Nenhuma obra, literária ou não, é 'inocente'. Sua 'culpa' está em ser resposta à vida, da forma como ela se manifesta para seu responsável autoral. E sua 'culpa' se agrava, quando o sujeito que a recebe joga com ela, pois no cenário desse jogo, estão suas expectativas pessoais, suas paixões - ou sua ausência de paixão. 
Essa tensão criada no ato de ler, especialmente, na leitura literária, traz desconforto para o leitor. O desafio que hoje se coloca, nos parece, é convencer os diferentes leitorados, brasileiros, sul-americanos, norte-americanos e, até, europeus, que esse desconforto é tão prazeroso quanto o conforto da exibição visual de filmes na TV, no cinema, no computador. Ou tão prazeroso quanto os inúmeros jogos eletrônicos que prendem jovens e adultos diante das muitas máquinas que nos cercam por horas a fio.

Leitores ampliam seus horizontes emocionais e intelectuais, adquirindo novas dimensões de saber e autocompreensão através de obras literárias. Esse é um dos motivos frequentes de recomendação da leitura de textos literários como complementação da educação da pessoa, como se uma percepção mais clara de certas 'realidades' pudesse emergir através da experiência literária (LEAHYDIOS, 2004, p. XXVIII).

O trecho acima, retirado do livro Educação literária como metáfora social: desvios e rumos, de Cyana Leahy-Dios, trabalha a questão da leitura literária, dando-lhe uma função de redenção e reconstrução do Sujeito. Segundo a pesquisadora, a leitura literária expande as competências emocionais e intelectuais dos leitores. Ligia Cademartori discute a convivência de diferentes textos, suportes e discursos na sociedade contemporânea, definindo parâmetros de concorrência entre o livro, as mídias, as linguagens...

[...] se o livro não concorre com outros meios, como televisão, rádio, periódico, computador, não escapa de concorrer com outros discursos, como os de natureza pragmática, política ou religiosa, disputa que vai gerar trágicas consequências. Os discursos, já se sabe, só existem em cruzamento (CADEMARTORI, 2009, p. 19).

A perspectiva humanista da supremacia da cultura livresca e literária, como instrumento de destaque individual na sociedade burguesa está se desmanchando. No século XIX e em boa parte do XX, dominar as letras, ser letrado, era uma situação que concedia ao indivíduo um lugar social com certos privilégios. As sociedades e as sociabilidades mudaram: no século XXI, as mídias, os suportes, as linguagens, as muitas discursividades não existem isoladamente como garantia de domínio intelectual, como base de poder em qualquer 
nível. Por conta da globalização dos saberes e métodos, todos esses espaços simbólicos estão vendo suas fronteiras se dissolverem.

Os leitores literários, hoje, formam um círculo por demais restrito e normalmente sucumbem ante os muitos textos com que se deparam. As reflexões de Leahy-Dios e Cademartori indicam que, embora tradicionalmente se defina o leitor como o indivíduo capaz de decifrar sinais gráficos, atribuindolhes sentidos, essa definição não é suficiente no cenário cultural contemporâneo. Ler é dirigir os olhos, o corpo e a alma a um texto - seja ele uma tessitura de palavras, seja uma escultura, uma pintura, a expressão facial ou corporal de uma pessoa, um prédio, uma praça, uma vitrine, um filme, um grafite no muro da escola - e começar a namorá-lo, acercar-se, apropriar-se dele.

Esse trânsito implica desejo, como em qualquer namoro. Tal desejo, impulso em direção a uma alteridade que nos provoca e nos faz perceber nossa incompletude permanente, não é natural, é produto das práticas culturais que nos formam e com as quais interagimos cotidianamente.

Tanto o sujeito (leitor) como o texto são históricos e culturais, isto é, carregam características que denunciam suas origens, expectativas e preferências. A interlocução entre ambos é transformadora. E isso é bastante lúdico e prazeroso no âmbito literário.

Retomando a linha de raciocínio esboçada parágrafos acima, o desejo a que nos referimos como tônica do ato da leitura ocorre tanto por parte do texto, que se dá a ver, faceiro, em sua sedutora materialidade, como por parte de quem o olha, instigado por seus mistérios, por seus jogos de luz e sombra, por suas sugestões de visualidade encantada e encantadora. Os atos de leitura literária, então, equivalem a atos de amor, de apaixonamento mútuo: o texto se contorce - e distorce até - com o prazer de se saber tocado pelo apetite do leitor e este exercita seu poder de sedução, ao se debruçar sobre o objeto que o provoca, buscando suas curvas, suas cores, seus sabores, seus perfumes.

A leitura literária demanda, para ser bem sucedida, o momento da aproximação, do envolvimento, dos pequenos presentes: um significado aqui, uma emoção ali, um arrepio, um suspiro, um pouco de medo, afinal, texto e leitor, até a abertura da primeira página, são quase ilustres desconhecidos. As fases iniciais desse processo de descoberta recíproca são fundamentais para a fruição prazerosa da leitura. 
O leitor é o sujeito desse encontro e de suas consequências. Como no amor, na leitura, não há manuais que garantam a vitória da empreitada. O leitor literário, então, como qualquer amante, é inseguro, deve ser inseguro, ele tem medo de interpretar erroneamente os sinais, tem medo de ser inadequado em suas intervenções, insistindo em idéias pouco criativas. Tem medo, ainda, de avançar demais, de fazer ligações indevidas. Para o leitor, o texto detém o poder, ele aprendeu, desde sempre, que os textos estão prontos quando chegam ao seu alcance. Mal sabe ele que o texto, sem sua presença transformadora, não é nada além de palavras impressas numa página qualquer.

Sem o leitor apaixonado e apaixonante, todos os textos do mundo se assemelhariam a pessoas solitárias e mal-humoradas - seriam estéreis, silenciosos e silenciados, mudos em sua inexistência fugaz. Esse casamento necessário entre texto e leitor, no entanto, nem sempre acontece com belas festas, com brinde e valsa.

Ninguém nasce sabendo namorar e ninguém nasce sabendo ler - seja a palavra, seja a imagem, seja o mundo. Assim como precisamos da ajuda dos familiares e amigos para aprendermos a seduzir nossos pares, também precisamos do apoio de pessoas mais experientes, que já dominam algumas estratégias/táticas de entrosamento com as textualidades que se acercam de nós e com as quais tentamos interagir, para aprendermos a dialogar com elas. Não existe uma técnica de leitura, uma estratégia de aproximação e apaixonamento. Há muitas, cada indivíduo cria a sua e deve passá-la adiante, sem preocupação com o sentido certo (ou errado) resultante da sua forma de ler.

Entendemos que as tessituras textuais, ou seja, as várias materialidades dos múltiplos textos que habitam nosso dia-a-dia, são fundamentais. Aquele que cria o texto literário introjeta neste, voluntaria ou involuntariamente, seus valores, suas visões de mundo, suas perspectivas históricas, filosóficas, religiosas, as quais se concretizam quer na seleção temática, quer na escolha vocabular, quer na combinação das cores, quer no limite dos traços, quer no foco da câmera, quer na melodia da música, quer na forma das roupas ou no tipo de maquiagem, ou na escolha dos vidros de um prédio, ou das flores no jardim de uma praça.

Daí, então, seria possível deduzirmos que a obra literária comanda a relação? Desenhamos neste artigo exatamente o contrário. Isso porque nada do que foi descrito e apontado no parágrafo anterior existe sem o olhar de um Sujeito. Temas, palavras, cores, formas, focos, sons, todos esses elementos 
que estruturam os textos que nos provocam só existem a partir da interação conosco. Recorremos a Bortoni-Ricardo, Machado e Castanheira:

[...] formar leitores autônomos significa formar leitores capazes de aprender a partir dos textos. Para isso, quem lê deve ser capaz de interrogar-se sobre sua própria compreensão, estabelecer relações entre o que lê e o que faz parte de seu acervo pessoal, questionar seu conhecimento e modifica-lo, estabelecer generalizações que permitam transferir o que foi aprendido para contextos diferentes (BORTONI-RICARDO; MACHADO; CASTANHEIRA, 2010, p. 56).

Assim, no processo da leitura literária, "seduzir" o leitor é peça chave. E por leitor, aqui, entendemos aquele Sujeito que se abre para a interlocução. Ele trava um rico diálogo com o texto, ampliando sua capacidade de reflexão e transformação.

O leitor literário está mesmo rareando cada vez mais, o leitor hoje lê de um jeito múltiplo, fragmentado, desdobrando-se em leituras muito diferentes dos textos da vida, talvez sua capacidade de refletir e sua habilidade de comparar textos se amplie. Vivemos uma época em que a ordem das sociabilidades mudou de familiar, interior e intimista para coletiva, exterior e urbana. Com isso, as formas de prazer também se espetacularizaram e excluíram a relação particular e concentrada do indivíduo com os textos, mas não diminuíram, necessariamente, a possibilidade transformadora desses novos atos de ler, nem dos textos lidos.

As formas de ler mudaram, porque nossas formas de relacionamento mudaram também. Isso é histórico e cultural. Ninguém mais leva sete anos namorando, Jacó nenhum serve a Labão para receber Raquel (referimo-nos à passagem bíblica e ao célebre poema camoniano), permanecendo fiel, apesar das armadilhas. O amor é rápido e fragmentado. A leitura também. O leitor, hoje, é um ser em processo de esfacelamento: ele precisa viver inúmeros papéis num só dia e esse modo de encenar-se a si mesmo acaba se tornando uma forma de repúdio a uma possível essencialidade. Para esse leitor que se nega como ser integral, que se constrói como quebra-cabeças em permanente incompletude, não pode haver um texto a ser lido num só jantar. Para esse leitor, cada jantar reúne um sem-número de textos literários em sua duração. Ler literatura não é algo sempre igual, o ato de ler muda no tempo e no es- 
paço. Isso não é bom, nem ruim, simplesmente é. Os variados contextos de leitura mudam, atualizam os textos e seus suportes (GALVÃO et BATISTA, 2005, p. 19).

$\mathrm{Na}$ tentativa de responder à provocação implicitada no título, tentamos amarrar nossas reflexões. A leitura foi tradicionalmente considerada marca de um lugar social privilegiado. Esse poder deu ao indivíduo condições especiais, enquanto as sociabilidades se definiam por critérios humanistas.

Com as transformações tecnológicas, culturais e sociais ocorridas entre o final do século XX e os primeiros anos deste século XXI, pensar a leitura literária e o leitor nos moldes passados significa inviabilizar a existência de ambos. Daí as tantas afirmações de que os jovens não lêem, a leitura está desacreditada, etc. Avaliar a leitura literária e o leitor hoje com olhos oitocentistas e/ou novecentistas é esvaziá-los de valor e significância.

Como construções históricas, sociais e culturais, leitura e leitor são, sim, pertinentes ao universo tecnológico em que vivemos. O homem contemporâneo, fragmentado e fragmentador, lê as textualidades que elabora e que o engendram de forma disseminada, rizomática. A leitura, agora, não é a do mergulho no romance. Ela se faz pela interação explícita e necessária de competências, repertórios e objetos: o Sujeito entra no romance, sai pela poesia, envereda pela música, corta caminho pelo filme, se dispersa no celular e volta para o romance, misturando tudo o que leu, num caldeirão de sentidos extremamente criativos e sedutores.

Ler literatura hoje é, mais do que nunca, um ato de amor, de apaixonamento, mas de amor livre, independente, múltiplo, desavergonhado. É um jantar de pratos variados e intercambiáveis. E transforma, sim. Não para homogeneizar o leitor e seu mundo. Mas para expor as fundamentais fraturas que os constituem.

\section{Referências Bibliográficas}

BORTONI-RICARDO, Stella Maris; MACHADO, Veruska Ribeiro; CASTANHEIRA, Salete Flores. Formação do professor como agente letrador. São Paulo: Contexto, 2010. CADEMARTORI, Ligia. O professor e a literatura para pequenos, médios e grandes. Belo Horizonte: Autêntica Editora, 2009.

COMPAGNON, Antoine. Literatura para quê? Tradução de Laura Taddei Brandini. Belo Horizonte: Editora UFMG, 2009. 
COSSON, Rildo. Letramento literário: teoria e prática. São Paulo: Contexto, 2009.

COSTA, Marta Morais da. Sempreviva, a leitura. Curitiba: Aymará, 2009.

CURCINO, Luzmara. Mutações do Suporte e dos Gêneros Discursivos: Inícios de Mudanças da Leitura e dos Leitores? In: AGUIAR, Vera Teixeira de e CECCANTINI, João Luís. Teclas e dígitos: leitura, literatura \& mercado. São Paulo: Cultura Acadêmica, 2010. P.13-24.

GALVÃO, Ana Maria de Oliveira et BATISTA, Antônio Augusto Gomes. Práticas de leitura, impressos, letramentos: uma introdução. In: GALVÃO, Ana Maria de Oliveira et BATISTA, Antônio Augusto Gomes (orgs.). Leitura: práticas, impressos, letramentos. $2^{\mathrm{a}}$. ed. 1 $^{\mathrm{a}}$. reimpressão. Belo Horizonte: Autêntica, 2005.

LEAHY-DIOS, Cyana. Educação literária como metáfora social: desvios e rumos. São Paulo: Martins Fontes, 2004.

YUNES, Eliana et PONDÉ, Glória. Leitura e leituras da literatura infantil. 2a . ed. São Paulo: FTD, 1989.

YUNES, Eliana. Tecendo um leitor: uma rede de fios cruzados. Curitiba: Aymará, 2009.

Recebido em 04 de maio e aprovado em 03 de junho de 2011. 